\title{
Role of barium swallow pharyngoesophagography in the management of globus pharyngeus
}

\author{
Fatma Caylakli ${ }^{1}$ (D)
}

Received: 26 July 2018 / Accepted: 31 July 2018 / Published online: 19 August 2018

c) Springer-Verlag GmbH Germany, part of Springer Nature 2018

\section{Dear Sir,}

I read the manuscript entitled "Globus pharyngeus: a review of etiology, diagnostics, and treatment" by Järvenpää et al. [1]. The manuscript is a valuable review about globus pharyngeus. Globus pharyngeus is a general symptom and the etiology is so controversial as the authors mentioned. Therefore, uniform investigation and treatment strategy is lacking. Patients with globus symptom are generally anxious and mostly think that they have a disease as malignancy. But they mostly do not complain about their fear of having malignancy to their specialist during examination. I agree with the authors about performing some examinations to convince the patients. The authors state that modified barium swallow study with esophagogram has no benefit in globus diagnostics. I disagree with them on this subject. Barium swallow pharyngoesophagography is useful to detect underlying benign characterisitc pathologies such as cervical osteophyte indentation, esophageal traction diverticulum, hiatal hernia, cricopharyngeal muscle spasm, achalasia, esophageal web, and Zenker diverticulum in patients with globus symptom [2]. Besides detecting these benign pathologies, finding normal results have positive effect on convincing and calming the patient because of the fear of having a disease. Barium swallow adds very little to the diagnosis of globus pharyngeus, but it plays a role in the reassurance particularly from the patients' perspective [3]. Therefore, barium swallow pharyngoesophagography has a positive role on clinicians' convincing the patients that the globus is harmless.

\section{Compliance with ethical standards}

Conflict of interest The authors declare no conflict of interest whatsoever arising out of the publication of this manuscript.

\section{References}

1. Järvenpää P, Arkkila P, Aaltonen LM (2018) Globus pharyngeus: a review of etiology, diagnostics, and treatment. Eur Arch Otorhinolaryngol 275(8): 1945-1953

2. Caylakli F, Yavuz H, Erkan AN, Ozer C, Ozluoglu LN (2006) Evaluation of patients with globus pharyngeus with barium swallow pharyngoesophagography. Laryngoscope 116(1):37-39

3. Mahrous AK, Kaoutzanis C, Amin K, Gluckman P (2012) Positive findings on barium swallow in patients presenting with a "sensation of a lump in the throat". Eur Arch Otorhinolaryngol 269(3):1047-1050
This comment refers to the article available online at https://doi. org/10.1007/s00405-018-5041-1.

\section{Fatma Caylakli}

fcaylakli@yahoo.com

1 Otorhinolaryngology Head and Neck Surgery, Baskent University School of Medicine, Adana Research and Medical Center, Gazipasa Mh. Baraj Cd, No 7, Seyhan, Adana, Turkey 